\title{
Rancang Bangun Otomatisasi Intensitas Cahaya, Suhu dan Kelembaban Untuk Budidaya Jamur Tiram Berbasis Mikrokontroler di Desa Kendal, Sekaran, Lamongan
}

\author{
Suharjanto *) \\ ${ }^{*}$ Program Studi Teknik Elektro, Fakultas Teknik, Universitas Islam Lamongan \\ email : suharjanto2014@gmail.com
}

\begin{abstract}
Abstrak
Budidaya jamur tiram dilakukan di daerah dataran tinggi yang memiliki temperatur yang rendah sedangkan pada daerah dataran rendah dibudidayakan pada kumbung-kumbung jamur. Agar pertumbuhan jamur dalam kumbung dapat optimal maka suhu dan kelembaban dari kumbung harus dijaga sesuai dengan kondisi alaminya. Di dataran rendah, pengaturan suhu dan kelembaban kumbung jamur masih dilakukan secara manual, sehingga kontrol otomatis diperlukan untuk mengatur suhu dan kelembaban kumbung jamur agar meringankan kerja petani jamur. Untuk menjaga kondisi kumbung yang ideal yaitu ruang budidaya yang memiliki suhu dan kelembaban $\pm 30^{\circ} \mathrm{C}$ dan $70 \%-90 \% \mathrm{RH}$, diperlukan alat berupa mist maker dan blower serta sensor DHT 11 untuk men-sensing dari suhu dan kelembaban ruang. Alat ini akan mengatur suhu dan kelambaban pada miniatur kumbung jamur secara otomatis, jika sensor DHT11 mendeteksi suhu $>30^{\circ} \mathrm{C}$ dan kelembaban $<70 \%$, maka water mist maker dan blower akan aktif secara otomatis sehingga akan mendinginkan dan melembabkan ruang kumbung jamur. Selain itu untuk fase pertumbuhan tubuh jamur memerlukan cahaya yakni \pm 300 lux, diperlukan lampu LED serta sensor LDR untuk men-sensing dari intensitas cahaya pada miniatur kumbung jamur. Alat ini akan mengatur intensitas cahaya secara otomatis, jika sensor LDR mendeteksi cahaya >300 lux maka lampu LED secara otomatis akan menyala.
\end{abstract}

Kata Kunci : Jamur, ATMega 328, sensor DHT 11, sensor LDR, mist maker

\section{PENDAHULUAN}

Pembudidayaan jamur tiram saat ini mengalami perkembangan yang pesat. Jamur tiram yang memiliki habitat alami di hutan, sekarang dapat dibudidayakan pada kumbung - kumbung jamur daerah dataran rendah. Agar pertumbuhan jamur dapat optimal maka suhu dan kelembaban daripada kumbung harus dijaga sesuai dengan kondisi idealnya.

Habitat alami jamur tiram secara alami ditemukan di hutan dibawah pohon berdaun lebar. Jamur tiram tidak memerlukan cahaya matahari yang banyak, di tempat terlindung miselium jamur akan tumbuh lebih cepat daripada di tempat yang terang dengan cahaya matahari berlimpah. Pertumbuhan miselium akan tumbuh dengan cepat dalam keadaan gelap/tanpa sinar. Pada masa pertumbuhan misellium, jamur tiram sebaiknya ditempatkan dalam ruangan yang gelap, tetapi pada masa pertumbuhan badan buah memerlukan adanya rangsangan sinar. Pada tempat yang sama sekali tidak ada cahaya badan buah tidak dapat tumbuh, oleh karena itu pada masa terbentuknya badan buah pada permukaan media harus mulai mendapat sinar dengan intensitas penyinaran 60-70\%. Pada budidaya jamur tiram suhu udara memegang peranan yang penting untuk mendapatkan pertumbuhan badan buah yang optimal. Pada umumnya suhu yang optimal untuk pertumbuhan jamur tiram, dibedakan dalam dua fase yaitu fase inkubasi yang memerlukan suhu udara berkisar antara $28-30{ }^{\circ} \mathrm{C}$ dengan kelembaban $60-70 \%$ dan fase pembentukan tubuh buah memerlukan suhu udara antara $22-28{ }^{\circ} \mathrm{C}$ dengan kelembaban $70-90 \%$.

\section{MAKSUD DAN TUJUAN}

Maksud dan tujuan dari perancangan ini adalah:

1. Merancang sebuah alat yang mampu mengatur intensitas cahaya, suhu serta kelembaban pada tempat budidaya jamur tiram secara otomatis.

2. Dapat mengetahui bahwa intensitas cahaya, suhu dan kelembaban dalam kumbung jamur sudah sesuai dengan standar.

\section{II.METODOLOGI}

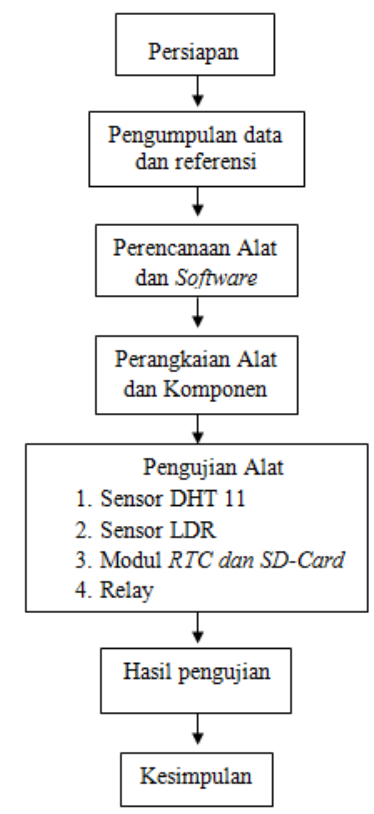

Gambar 1. FlowChart Perencanaan Sistem 
Analisis dalam penelitian ini dilakukan dalam beberapa tahapan sebagai berikut :

1. Pengumpulan data dan referensi yang dilakukan seperti penentuan jenis sensor yang digunakan, jenis mikrokontroler, jenis relay, dan jenis data logger yang digunakan.

2. Pada tahap Perencanaan hardware/alat dan software ini seperti membuat rancangan sensor suhu dan kelembaban, sensor cahaya, rancangan relay, rancangan sistem data logger menggunakan modul RTC dan perancangan pencatatan data menggunakan modul SD-Card.

3. Perakitan atau perangkaian seluruh rangkaian sensor DHT11 dan rangkain sensor LDR beserta rangkaian sistem data logger menggunakan modul RTC dan perancangan pencatatan data menggunakan modul SD-Card.

4. Pengujian sensor DHT11 dengan mikrokontroler arduino ATmega328.

5. Pengujian sensor LDR dengan mikrokontroler arduino ATmega328.

6. Pengujian Modul RTC dengan data dari mikrokontroler arduino ATmega328.

7. Pengujian modul SD-Card dengan data dari mikrokontroler arduino ATmega3.

8. Menarik hasil pengujian sensor DHT11, sensor LDR, sistem pecatatan data Micro-SD,.

9. Mengumpulkan data hasil pengujian dan di simpulkan menjadi hasil penelitian.

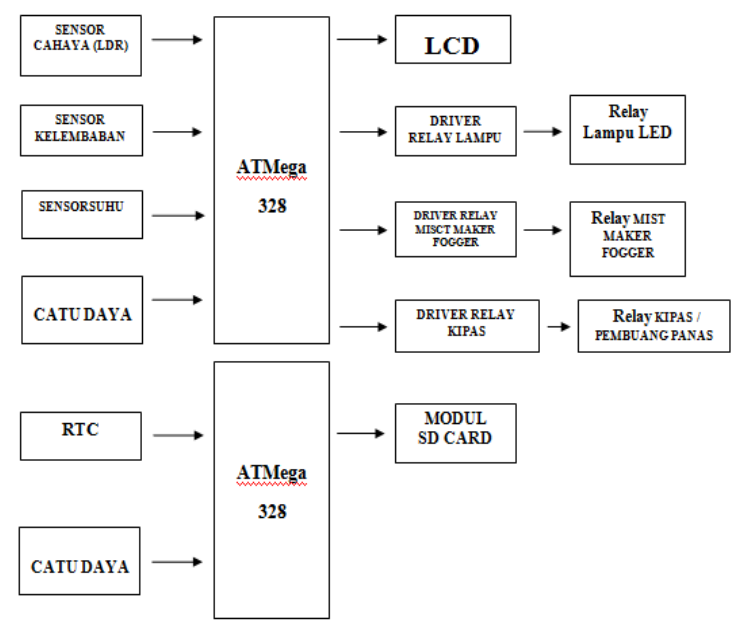

Gambar 2. Digram Blok Perencanaan Alat

\section{Fungsi Bagian Per Blok}

Dari diagram block perencanaan alat diatas, dapat diuraikan sebagai berikut :

1. Sensor LDR ini memungkinkan kita untuk melakukan pendeteksian cahaya dan dapat mengalami perubahan resistansinya apabila mengalami perubahan penerimaan cahaya.

2. Sensor Suhu dan Kelembaban (LDR) berfungsi untuk pendeteksian suhu dan kelembaban pada suatu ruangan.
3. Mikrokontroler ATMega 328 adalah sebuah mikrokontroller yang berfungsi sebagai otak atau sistem yang memproses kerja relay, dan pengirim data ke RTC dan SD-Card.

4. LCD atau Liquid Crystal Display adalah perangkat penampil data atau nilai cahaya, suhu, dan kelembaban yang sudah diterima dan diproses Arduino.

5. Driver relay adalah rangkaian komponen yang berfungsi untuk mengaktifkan relay, selain itu driver relay ini juga mejadi proteksi (pengaman) pin kaki Arduino agar tidak terhubung langsung ke relay karena untuk menjaga lifetime komponen Arduino.

6. Relay berfungsi sebagai pemutus / menghidupkan kipas fan, lampu LED, dan mist maker.

7. RTC berfungsi sebagai sumber data waktu baik berupa data jam, hari, bulan maupun tahun.

8. SD-Card berfungsi sebagai penyimpan semua data yang diperoleh dari dua sensor dan RTC.

9. Adaptor catu daya merupakan sumber tegangan DC.

\section{Perancangan Rangkaian Sensor DHT11}

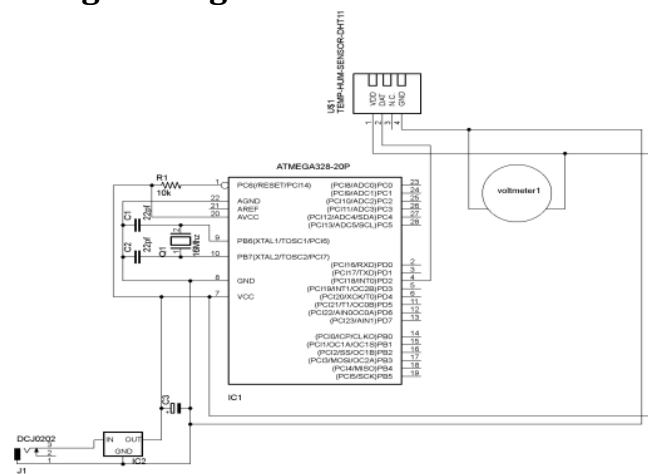

\section{Gambar 3. Skema Pemasangan dan Pengujian Sensor DHT11}

Sensor suhu dan kelembaban ini digunakan untuk mendapatkan parameter suhu dan kelembaban dalam kumbung jamur sehingga dapat mengetahui berapa suhu dan kelembaban pada kumbung jamur. Pada pembuatan sensor suhu dan kelembaban ini menggunakan sensor DHT11. Metode pengujian yang dilakukan adalah dengan menghubungkan sensor ke arduino kemudian hasil dari pembacaan arduino di serial monitor akan dibandingkan dengan pengukuran thermometer. 


\section{Perancangan Rangkaian Sensor LDR}

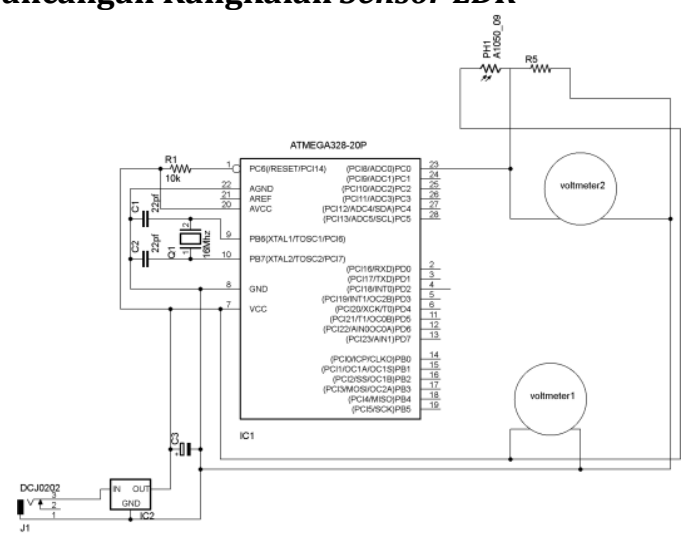

Gambar 4. Skema Pemasangan dan Pengujian Sensor LDR

Sensor cahaya ini digunakan untuk mendapatkan parameter cahaya dalam kumbung jamur sehingga dapat mengetahui berapa intensitas cahaya pada kumbung jamur. Pada pembuatan sensor cahaya ini menggunakan sensor LDR. Metode pengujian yang dilakukan adalah dengan menghubungkan sensor ke arduino kemudian hasil dari pembacaan arduino di serial monitor akan dibandingkan dengan lux meter.

\section{Perancangan Rangkaian Modul RTC}

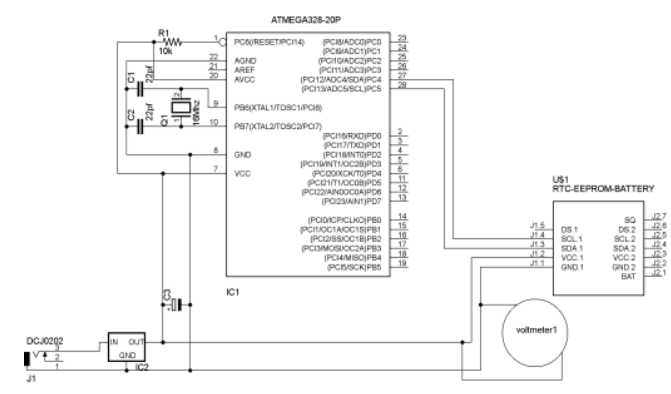

Gambar 5. Skema Pemasangan dan Pengujian Modul RTC

Modul RTC ini digunakan untuk mencatat data waktu berupa jam, tanggal, bulan, serta tahun untuk selanjutnya akan dikirim atau disimpan di SD-Card. Mitode pengujian Modul RTC dilakukan dengan menghubungkan ke arduino kemudian hasil dari pencatatan RTC akan di lihat pada SD-Card.

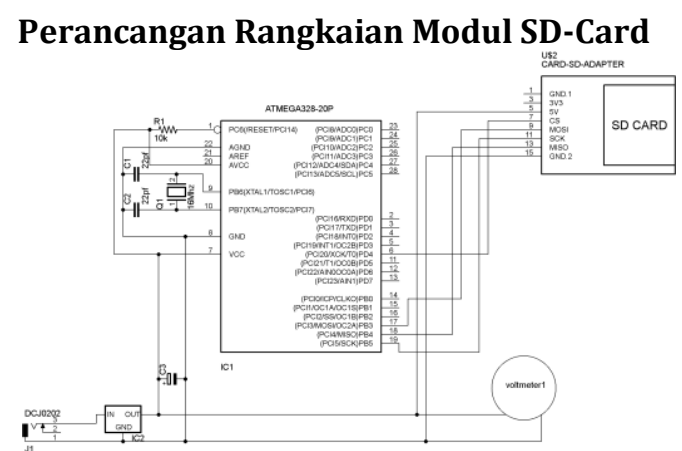

Gambar 6. Skema Pemasangan dan Pengujian Modul SD-Card

Modul SD-Card ini digunakan untuk menyimpan informasi data dari sensor dan Modul RTC untuk selanjutnya hasil akan dilihat melauli handphone atau Pc. Mitode pengujian Modul SD-Card dilakukan dengan menghubungkan ke arduino dan memberi coding program SD-Card untuk menyimpan data yang sudah dikumpulkan.

\section{Perancangan Rangkaian Secara Keseluruhan}

Perakitan perangkat keras yaitu dengan membuat rangkaian skema pada software Fritzing, kemudian hasil gambar skema rangkaian dirangkai dengan PCB lubang, komponen disusun sesuai skema rangkaian yang telah dibuat. Pada proses ini komponen arduino, sensor DHT 11 , sensor LDR, LCD 16x2, modul RTC, modul SDCard, sistem relay dan soket dipasang ke PCB. Selanjutnya, penyambungan antar PCB menggunakan kabel.

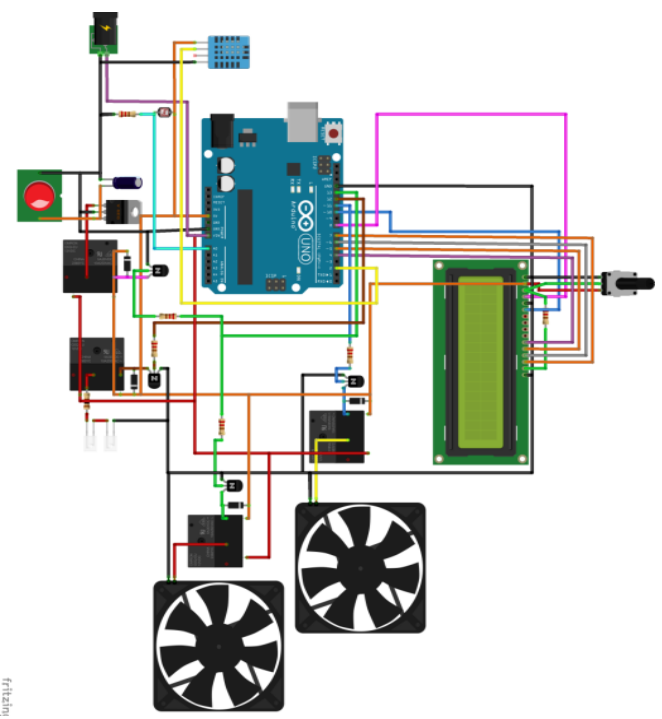

Gambar 7. Skema Pemasangan dan Pengujian Rangkaian Secara Keseluruhan 


\section{HASIL DAN PEMBAHASAN}

\section{Hasil Pengujian Rangkaian}

\section{A. Pengujian Rangkaian Sensor DHT11}

Pada tahap ini dilakukan pengujian pada hasil pembacaan suhu dan kelembaban yang sudah dikoversi oleh sistem program Arduino. Sensor DHT11 ini mampu mengukur suhu dan kelembaban. Pada tabel di bawah ini merupakan hasil pengujian sensor DHT11. Pengujian ini dilakukan dengan cara pengukuran pada suhu masukan, menggunakan di serial monitor Arduino.

Tabel 1. Tabel Data Hasil Pengujian Rangkaian Sensor DHT11

\begin{tabular}{|c|c|c|c|c|}
\hline \multirow{2}{*}{$\begin{array}{c}\text { Hasil } \\
\text { pengukuran } \\
\text { Voltmeter 1 } \\
\text { (Volt) }\end{array}$} & \multirow{2}{*}{$\begin{array}{c}\text { Hasil } \\
\text { pengukuran } \\
\text { Voltmeter } 2 \\
\text { (Volt) }\end{array}$} & \multirow{2}{*}{$\begin{array}{c}\text { Hasil } \\
\text { pengukuran } \\
\text { termometer }\end{array}$} & \multicolumn{2}{|c|}{$\begin{array}{l}\text { Hasil Pengukuran sensor } \\
\text { DHT11 }\end{array}$} \\
\hline & & & Suhu & Kelembaban \\
\hline 5.0 & 0,34 & 28 & 30 & 80 \\
\hline 5.0 & 0,32 & 30 & 31 & 75 \\
\hline 5.0 & 0,38 & 32 & 32 & 75 \\
\hline 5,0 & 0,37 & 32 & 33 & 65 \\
\hline
\end{tabular}

\section{B. Pengujian Rangkaian Sensor LDR}

Pada tahap ini dilakukan pengujian pada hasil pembacaan intensitas cahaya yang sudah dikonversi oleh sistem program arduino. Sensor LDR ini mampu membaca intensitas cahaya pada miniatur kumbung jamur. Pengujian sensor cahaya (LDR) sebagai pengukur kondisi cahaya di dalam ruangandilakukan untuk mengetahui data yang didapat dari sensor LDR tersebut.

Tabel 2. Tabel Hasil Pengujian Sensor LDR

\begin{tabular}{|c|c|c|c|c|c|c|c|}
\hline $\begin{array}{c}\text { Intensitas } \\
\text { cahayadengan } \\
\text { aplikasilux } \\
\text { meter }\end{array}$ & $\begin{array}{c}\mathrm{R} 2 \\
\text { (resistansi } \\
\text { LDR) }\end{array}$ & $\begin{array}{c}\text { Rl } \\
\text { (Tetap) }\end{array}$ & Vin & $\begin{array}{l}\text { Perbandingan } \\
\mathrm{R} 2 /(\mathrm{R} 1+\mathrm{R} 2)\end{array}$ & V out & $\begin{array}{l}\text { Nilai Sensor } \\
\text { Pada Senial } \\
\text { Monitor } \\
\text { Arduino }\end{array}$ & $\begin{array}{c}\text { Status Relay } \\
\text { Lampu }\end{array}$ \\
\hline $750 \mathrm{lux}$ & $300 \mathrm{ohm}$ & $5.6 \mathrm{k}$ & $5 \mathrm{v}$ & 0.05 & $0.25 \mathrm{v}$ & 750 & Off \\
\hline $200 \operatorname{lux}$ & $2 \mathrm{k}$ & $5.6 \mathrm{k}$ & $5 \mathrm{v}$ & 0.26 & $1.3 \mathrm{v}$ & 200 & Off \\
\hline $30 \operatorname{lux}$ & $6 \mathrm{k}$ & $5.6 \mathrm{k}$ & $5 \mathrm{~V}$ & 0.51 & 2.55 & 30 & On \\
\hline
\end{tabular}

\section{Pengujian Rangkaian Relay}

Pada pengujian ini menggunakan 3 buah relay HKE HRS4H-S-DC 5V tegangan rendah, 5VDC, sehingga dapat langsung dihubungkan pada sistem mikrokontroler. Tipe relay tersebut adalah SPDT (Single Pole Double Throw): 1Common, $1 \mathrm{NC}$ (Normally Close), dan $1 \mathrm{NO}$ (Normally Open). Memiliki daya tahan sampai dengan 10A dan dapat langsung dihubungkan pada mini sistem arduino. Pin pengendali dapat dihubungkan dengan pin port mikrokontroler mana saja, sehingga membuat pemrograman dapat leluasa menentukan pin mikrokontroler yang akan digunakan sebagai pengendali. Berikut tampilan rangkaian relay.
Tabel 3. Tabel Hasil Pengujian Relay

\begin{tabular}{ccccccc}
\hline \multirow{2}{*}{ Cahaya } & \multirow{2}{*}{ Suhu } & Kelembaban & \multicolumn{5}{c}{ Status relay } \\
\cline { 4 - 7 } & & & Lampu & $\begin{array}{c}\text { Kipas } \\
\text { exhaust }\end{array}$ & $\begin{array}{c}\text { Misk } \\
\text { maker }\end{array}$ & $\begin{array}{c}\text { Kipas } \\
\text { Inhaust }\end{array}$ \\
\hline 100 & 27 & 80 & On & Off & Off & Off \\
\hline 120 & 30 & 60 & On & On & On & On \\
\hline 250 & 28 & 75 & Off & Off & Off & Off \\
\hline 200 & 32 & 75 & Off & On & Off & Off
\end{tabular}

\section{Pengujian Rangkaian Keseluruhan}

Pengujian ini adalah pengujian secara langsung dimana semua bagian dihubungkan menjadi sebuah sistem yang diinginkan pada saat merancang alat ini. Pengujian ini di lakukan dengan sumber Adaptor 12V. Tegangan input yang diberikan ada dua yaitu tegangan input $12 \mathrm{~V}$ untuk mikrokontroler ATMega328 dan sertategangan $5 \mathrm{~V}$ untuk rangkaian Relay dan sensornya.

Tabel 4. Tabel Hasil Pengujian Keseluruhan

\begin{tabular}{cccccccc}
\hline \multirow{2}{*}{ Cahaya } & Suhu & Kelembaban & \multicolumn{4}{c}{ Status relay } & Keterangan \\
\cline { 4 - 7 } & & Lampu & $\begin{array}{c}\text { Kipas } \\
\text { exhaust }\end{array}$ & $\begin{array}{c}\text { Misk } \\
\text { maker }\end{array}$ & $\begin{array}{c}\text { Kipas } \\
\text { inhaust }\end{array}$ & \\
\hline 100 & 27 & 80 & On & Off & Off & Off & sukses \\
\hline 120 & 30 & 60 & On & On & On & On & sukses \\
\hline 250 & 28 & 75 & Off & Off & Off & Off & sukses \\
\hline 200 & 32 & 75 & Off & On & Off & Off & sukses \\
\hline 150 & 29 & 65 & On & Off & On & On & Sukses
\end{tabular}

\section{Pembahasan}

Dari pengujian yang telah dilakukan, pengujian sensor suhu dan kelembaban, sensor cahaya dan sampai pengujian keseluruhan pada setiap bagian berfungsi dengan baik. Kedua sensor dapat bekerja dengan baik. Selanjutnya data sensor ditampilkan pada LCD 16x2.

Pada pengujian pertama dilakukan dengan mengukur suhu dan kelembaban pada miniatur kumbung jamur yang terhubung ke sensor DHT11 dan didapatkan hasil pengukuran yaitu suhu $30 \mathrm{C}$ dan kelembaban $80 \%$. Pada pengujian kedua dilakukan dengan mengukur intensitas cahaya yang terhubung pada sensor LDR dan didapatkan hasil pengukuran 250. Dari serangkaian percobaan sensor DHT11 dan LDR dapat membaca suhu, kelembaban serta intensitas cahaya.

Tahap selanjutnya yakni pengujian data logger dimana RTC bekerja dengan baik menentukan data waktu yakni tahun, bulan, tanggal, serta jam. SD-Card juga bekerja dengan baik menyimpan semua data dari kedua sensor serta data dari RTC 


\section{PENUTUP}

\section{Kesimpulan}

Berdasarkan hasil penelitian perancangan alat otomatisasi intensitas cahaya, suhu dan kelembaban pada kumbung jamur berbasis mikrokontroler maka dapat diambil kesimpulan:

1. Merancang alat otomatisasi intensitas cahaya, suhu, dan kelembaban menggunakan mikrokontroler dimulai dengan merakit perangkat keras kemudian merancang perangkat lunak untuk menjalankan perintah yang di inginkan, yaitu dengan membuat skema rangkaian pada sostware eagle, kemudian hasil gambar skema rangkaian dirangkai dengan PCB lubang, komponen disusun sesuai rangkaian yang telah dibuat, komponen yang dibutuhkan adalah Mikrokontroler ATMega 328, sensor DHT11, sensor LDR, modul RTC, modul SDCard, LCD 16x2 dan sistem relay dipasang ke PCB rangkaian. Selanjutnya memasukkan program kedalam arduino sehingga alat dapat berjalan dengan baik.

2. Untuk mengetahui apakah intensitas cahaya, suhu serta kelembaban pada kumbung jamur sesuai dengan standar adalah dengan cara melakukan serangkaian pengujian terhadap alat yang direncanakan, pengujian pertama dilakukan dengan mengukur suhu dan kelembaban pada miniatur kumbung yang terhubung ke sensor DHT11. Pada pengujian kedua dilakukan dengan mengukur intensitas cahaya yakni dengan sensor LDR. Tahap selanjutnya yakni melihat hasil data dari pengujian yang sudah tersimpan pada Micro-SD.

\section{PUSTAKA}

[1] Agromedia, 2006. Budi Daya Jamur Konsumsi.Agromedia Pustaka, Jakarta.

[2] Eko Wahyu Santoso. 2016. Prototype Penyiram Tanaman Otomatis Dengan Sensor Kelembapan Tanah Berbasis Mikrokontroller ATmega 328. Tugas Akhir. Universitas Islam Lamongan.

[3] Fandi Budiawan, Arman Jaya, ST.MT, Drs.Irianto,MT. 2015. Pengaturan Suhu dan Kelembaban Pada Miniatur Kumbung Untuk Meningkatkan Produktifitas Jamur Tiram. Tugas Akhir. Surabaya.

[4] Heri Guston Pintoyo. 2012. Alat Pengatur Suhu Otomatis Untuk Ruangan Tanaman Jamur Tiram Berbasis ATMega16. Tugas Akhir. Universitas Muhammadiyah Ponorogo.

[5] Nurfalah, Muhammad. 2015. "Makalah Arduino dan Raspberry PI Mikrokontroler". Makalah. Teknik Elektro. Universitas Tadulako. Palu.

[6] Haqqi Prananda. 2012. Prototype Sistem Pengendalian dan Monitoring Suhu dan Kelembaban Pada Media Tanam Jamur Tiram
Berbasis Logika Fuzzy. Tugas Akhir. Universitas Jember :

[7] Kotanimura. 2012. Habitat Jamur Tiram. Jember:

[8] Susilawati. 2010. Petunjuk Teknis Budidaya Jamur Tiram. Jurnal Sumatra Selatan :

[9] Theriatama Silva Kusuma. 2011. Rancang Bangun Pengendalian Suhu dan Kelembaban Pada Miniatur Kumbung Jamur Tiram. Tugas Akhir. Universitas Diponegoro Semarang:

[10] Yuliana. 2012. Simulasi Pengendalian Temperatur dan Kelembaban Pada Ruang Budidaya Jamur Tiram Berbasis Mikrokontroler. Tugas Akhir. Universitas Pembangunan Nasional "veteran” Surabaya 
